\title{
FUNDAMENTO Y LÍMITES DE LA IMPUNIDAD POR COLISIÓN DE DEBERES EN DERECHO PENAL
}

Alejandra Verde

\section{INTRODUCCIÓN}

Juan Pablo Alonso, en su artículo Normas penales y conflicto de deberes, plantea la existencia de una contradicción normativa entre los artículos 176 inc. $3^{\circ}$ y 302 inc. $1^{\circ}$ del $\mathrm{CP}$ argentino. Dicho autor presenta el siguiente caso: una persona libra un cheque a uno de sus proveedores y cuando éste lo deposita para cobrarlo el cheque es rechazado por falta de fondos. Por ello, el proveedor dentro de los treinta días de su rechazo intima al librador para que en el plazo de 24 horas abone la suma de dinero correspondiente. Pero en el período de tiempo ubicado entre el rechazo del cheque y la intimación al pago, el agente librador es declarado en quiebra 
y su patrimonio es intervenido por un juez y administrado por un síndico. Por lo tanto, en ese momento el agente se encuentra inserto en un dilema: pagar o no pagar. Él, en efecto, tendrá por un lado el deber jurídico que surge de la primera de las normas enunciadas, esto es, el deber de no pagar el cheque, ya que si lo hace violaría la pars conditio creditorum; y, por otro lado, tendrá el deber jurídico que surge de la segunda norma mencionada: el deber de pagar el cheque dentro del plazo de 24 horas desde que el banco lo intimó a hacerlo, pues, si no lo hace, incurrirá en un delito contra la fe pública.

Por ello Alonso concluye que el sujeto, pague o no pague, no podrá ser objeto de sanción penal por ausencia de antijuridicidad, toda vez que dicha persona no tendría la "posibilidad teórica de satisfacer ambos deberes jurídicos, ya que un deber (el de pagar) es la negación del otro (el de no pagar). Por lo tanto, no existe la posibilidad teórica normativa de satisfacer ambos deberes jurídicos al mismo tiempo"1.

No coincido, sin embargo, con la solución que Juan Pablo Alonso propone para el caso de análisis. A mi juicio, el conflicto de deberes planteado encuentra sencilla solución en el ordenamiento jurídico argentino, concretamente en el art. 34 inc. $4^{\circ}$ del CP. Esta norma prescribe que no serán punibles las acciones efectuadas por un agente en cumplimiento de un deber jurídico. En este sentido, a mi entender, sólo será punible el agente que pague el cheque (art. 176 inc. $3^{\circ}$ del $\mathrm{CP}$ argentino); mientras que, si no lo paga, su accionar estará justificado por el art. 34 inc. $4^{\circ}$ del CP, por lo que carecerá de antijuridicidad la conducta típica prescripta en el art. 302 inc. $1^{\circ}$ del CP, dado que, a mi juicio, debe apoyarse la opinión (dominante) que sostiene que el art. 34 inc. $4^{\circ}$ del CP opera como causa de justificación. Las razones que justifican mis puntos de vista se expondrán en el punto III) del presente trabajo. En el punto II), en tanto, se expondrá con algún detalle la tesis de Alonso, con el objetivo de dotar al presente trabajo de independencia descriptiva.

\section{LA posición de Alonso}

Alonso presenta, en primer lugar, dos definiciones de deber jurídico; a una de ellas la llama estándar y a la otra kelseniana. Explica

${ }^{1}$ Alonso, Juan Pablo, Normas penales y conflicto de deberes, pág. 57. 
que la definición a la que denomina estándar es aquella que, en forma explícita, establece la obligación de hacer o no hacer determinada conducta. La kelseniana en cambio, es la que establece una sanción para el caso de que una persona realice la conducta contraria a la que obliga la norma. Son ejemplos del primer caso enunciados como "es obligatorio no matar a otro" o "es obligatorio conducir por el lado derecho de la calzada"; mientras que son ejemplos del segundo las normas de derecho penal, como el art. 79 del CP argentino, que reza: "se impondrá la pena de 8 a 25 años de prisión o reclusión a quien matare a otro". En efecto, si se tiene en cuenta la concepción kelseniana puede advertirse que de ese artículo del CP surgen dos conductas obligatorias: una con relación a los ciudadanos, que tienen la obligación de no matar a otro, y otra con relación a los jueces, que tienen la obligación de imponer la sanción prevista en la norma para el caso que una persona no cumpla con esta obligación que le cabe ${ }^{2}$.

Así Alonso, en segundo lugar y siguiendo a Kelsen, sostiene que hay dos clases de normas, una primaria dirigida al juez y otra secundaria dirigida a los ciudadanos. Afirma también que ambas normas son de obligación, pero que se diferencian en cuanto a su destinatario y según sea este deber explícito o no. A partir de este análisis se refiere entonces a dos clases de sistemas: el sistema primario (del juez) y el sistema secundario (de los ciudadanos), y explica en qué consisten cada uno de ellos. En este sentido, establece que un subconjunto de normas primarias regula la actividad sancionatoria del juez penal respecto de lo que él llama -siguiendo a Alchourrón y Bulygin- un Universo del Discurso determinado; mientras que un subconjunto de normas secundarias regula la conducta de los ciudadanos respecto de otro Universo de Discurso determinado. A partir de estas clasificaciones efectúa relaciones entre normas y deberes jurídicos en ambos sistemas y entre ellos, es decir, según quienes sean los destinatarios de las normas $^{3}$.

En tercer lugar, el autor analiza relaciones entre el "sistema del juez" y el "sistema de los ciudadanos" en el ámbito del derecho penal, ante un conflicto entre dos normas jurídicas y sus correlativos

\footnotetext{
${ }^{2}$ Alonso, op.cit., pp. 25 y ss.

${ }^{3}$ Alonso, op. cit., pp. 25 y ss.
} 
deberes jurídicos, y en particular reacciones del sistema normativo del juez ante la existencia de estos conflictos en el sistema del ciudadano. El autor analiza las dos normas penales citadas ya en la Introducción: los arts. 176 inc. $3^{\circ}$ y 302 inc. $1^{\circ}$ del CP argentino, y desde diferentes ópticas, según los enfoque desde cada uno de los sistemas descriptos. En efecto, las normas primarias que surgen de esos artículos del $\mathrm{CP}$ según el sistema del juez son: a) "los jueces deberán imponer una pena de prisión de 2 años como mínimo y 6 años como máximo e inhabilitación especial de 3 años como mínimo y 10 años como máximo a quien, encontrándose sometido a las reglas del concurso y declarado en quiebra, pague una deuda fuera de las reglas que establece el concurso"; y b) "los jueces deberán imponer una pena de prisión de 6 meses como mínimo a 4 años como máximo e inhabilitación especial de 1 año como mínimo y 5 años como máximo a quien haya librado un cheque sin provisión fondos y 24 horas después de haber sido intimado por el banco a estos efectos no abone la suma debida"4.

Ante ello, Alonso plantea el conflicto ya descrito en la Introducción: qué debe hacer aquel que, habiendo librado un cheque, es luego declarado en quiebra y, posteriormente, intimado a pagar ese cheque por falta de fondos. Así, Alonso muestra la perplejidad que esto generaría en el sistema del juez si el agente paga el cheque: el juez tendrá el deber jurídico de imponerle la pena establecida en el art. 176 inc. $3^{\circ}$ del $\mathrm{CP}$, puesto que violaría la pars conditio creditorum; mientras que, si no lo abona, el juez deberá imponerle la pena prevista en el art. 302 inc. $1^{\circ}$ del CP, porque cometería un delito contra la fe pública ${ }^{5}$.

Alonso efectúa el mismo análisis con relación a los deberes jurídicos que surgen de las dos normas penales en cuestión, pero desde la óptica del sistema del ciudadano. En efecto, con base a los mismos ejemplos sostiene que el ciudadano, de acuerdo a lo prescripto en el art. 176 inc. $3^{\circ}$ del $\mathrm{CP}$, tiene el deber jurídico de no pagar el cheque, pero según el art. 302 inc. $1^{\circ}$ tiene el deber jurídico de pagarlo. En el primer caso, ese deber jurídico se fundamenta en que el ciudadano no debe violar la regla de la pars conditio creditorum y, en el segundo caso, porque no debe incurrir en un delito contra la fe pública.

\footnotetext{
${ }^{4}$ Alonso, op. cit., pp. 28 y ss.

${ }^{5}$ Alonso, op. cit., pp. $42 \mathrm{y}$ ss.
} 
Así planteado el problema, Alonso, siguiendo a Alf Ross, sostiene que se está ante un típico caso de contradicción normativa, pues se trata de dos normas que poseen inconsistencia fáctica, a la cual el autor denomina "parcial-parcial", en tanto ambas regulan la misma acción: pagar el cheque rechazado, pero de manera deónticamente incompatible (una norma -art. 302- obliga a pagar el cheque, y la otra norma -art. 176- prohíbe pagarlo).

Alonso, con todo, sostiene que el conflicto no se presenta a nivel del sistema primario ya que el juez se encontrará, según él, ante la obligación de condenar al agente sea cual fuera la acción que éste efectúe; es decir, si el agente paga deberá ser condenado según lo prescripto por el art. 176 inc. $3^{\circ}$ del CP; y si no paga por el art. 302 inc. $1^{\circ}$ del CP. Sin embargo, Alonso se plantea el interrogante de si, no obstante la no conflictividad en el sistema primario, el juez puede ignorar la conflictividad que, según el referido autor, existe en el sistema secundario.

Después de comparar y relacionar estas normas penales y los deberes jurídicos que surgen de ellas en cada uno de los sistemas establecidos, el autor procede a determinar las relaciones posibles que surgen a partir de ello y de las interacciones entre estos dos sistemas. Finalmente, plantea el problema de cómo se debe solucionar este conflicto y establece las siguientes posibilidades: 1) condenar bajo cualquier supuesto; 2) condenar bajo un supuesto y absolver bajo el otro (dando prevalencia a un artículo sobre el otro); 3) absolver bajo cualquier supuesto. A continuación se expondrán los argumentos empleados por Alonso para rechazar las dos primeras posibilidades, y para aceptar la tercera.

\section{a) Condena bajo cualquier supuesto}

Alonso, con relación a la primera de las posibilidades sugeridas, refiere que un argumento a su favor sería que "la sanción penal procede porque el agente se colocó voluntariamente en la situación de estar intimado al pago de un cheque rechazado en condiciones de sujeción a las reglas de un concurso (o quiebra). En tal situación, pagar o no pagar el cheque se torna irrelevante; toda vez que, pague o no 
pague, procederá la sanción penal"6. Pero el autor rechaza esta posibilidad y sostiene, críticamente, que de las normas primarias en cuestión se derivaría una nueva norma primaria que establecería lo siguiente: "si un agente sujeto a las reglas del concurso, declarado en quiebra, emite un cheque rechazado por no disponer de fondos suficientes, pague o no pague el cheque en cuestión, el juez tendrá la obligación de sancionarlo penalmente"7. Respecto de ello, afirma que el nuevo tipo resultante torna indominable para el agente una acción que, en los dos tipos de origen, lo son, y concluye adhiriendo a la doctrina dominante y rechazando que siempre proceda la condena, por cuanto si un elemento del tipo no es dominable para el autor no puede existir imputación objetiva, por lo que se estaría ante un caso de ausencia de tipicidad $^{8}$.

En esa misma línea argumental en contra de esta posibilidad de solución, Alonso sostiene también que afirmar la creación de una nueva norma podría violar el principio de legalidad. Afirma en este sentido que la derivación de este nuevo tipo penal a partir de los tipos originales es una consecuencia paradojal y que el nuevo tipo que se crea es incomprensible, puesto que no permite captar a qué bien jurídico tutela, y esto último es precisamente lo que vulneraría el principio de legalidad?

Asimismo, Alonso no está de acuerdo con que el sistema secundario sea irrelevante para el juez y que a éste sólo le quepa guiarse por el sistema primario. En este sentido, afirma que "un conflicto de deberes jurídicos puede llevar a un agente a cumplir un deber en desmedro de otro porque considera, con o sin razón, que uno de los deberes prevalece sobre el otro. Si el agente eligió cumplir con el deber superior, su accionar típico se encontrará justificado"10. Y aclara que Zaffaroni considera que se trata de una causa de atipicidad por ausencia de antinormatividad, puesto que requiere la consideración conglobada de ésta con las deducidas de los otros tipos penales.

Finalmente, Alonso insiste en que, en el caso de análisis, la condena bajo cualquier supuesto es improcedente sin importar la

\footnotetext{
${ }^{6}$ Alonso, op. cit., p. 43.

${ }^{7}$ Alonso, op. cit., p. 44.

${ }^{8}$ Alonso, op. cit, p. 45.

${ }^{9}$ Alonso, op. cit., p. 46-47.

${ }^{10}$ Alonso, op. cit., p. 47-48. 
posición sistemática que se asuma para la fundamentación de la exclusión del ilícito.

\section{b) Condena bajo un supuesto y absolución bajo el otro}

Teniendo en cuenta una postura doctrinaria muy difundida que determina que ante un conflicto de deberes siempre uno de ellos prevalece sobre el otro y que ello se logra a través de una hermenéutica adecuada, Alonso quiere demostrar que resulta difícil o imposible determinar, en este caso, cuál de los dos deberes jurídicos es el jerárquicamente superior y afirma que, en el supuesto del delito de quiebra, lo que la norma protege es el patrimonio del deudor como garantía común de los acreedores, mientras que en el delito de cheque lo que la norma protege es la fe pública, es decir, la previsibilidad y fiabilidad del mercado financiero de títulos de crédito. Y agrega que en el caso de análisis tampoco puede afirmarse cuál de los dos es más importante en función de la pena atribuida a su agresión, atento que las escalas penales, según su criterio, no presentan diferencias significativas. En definitiva, para Alonso los bienes jurídicos que las normas en cuestión tutelan son de diversa índole, protegen distintas situaciones y apuntan hacia principios diferentes, y por ello, a su juicio, determinar cuál de los dos es el que debe prevalecer en desmedro del otro es prácticamente imposible. Concluye entonces sosteniendo que la única posibilidad defendible es la de "absolución bajo cualquier supuesto"11.

\section{c) Absolución bajo cualquier supuesto}

Alonso, como ya se ha visto, adhiere a la postura a la que se refiere este subtítulo. Sostiene que no es posible analizar cuál de los dos deberes jurídicos en conflicto prevalece y cuál cede, pues se trata de deberes jurídicos prácticamente equivalentes y entiende que, por esta razón, no es posible aplicar una sanción al agente por el incumplimiento de uno de ellos. Y sostiene que si el conflicto de deberes jurídicos es irresoluble para el agente, cualquiera sea la conducta que lleve a cabo

\footnotetext{
${ }^{11}$ Alonso, op. cit., p. 54.
} 
-en este caso: pagar o no pagar-, no procedería sanción penal. Explica que esta consecuencia, según la tesitura de Zaffaroni, se fundamentará por atipicidad conglobante, toda vez que el poder punitivo no puede colocar a los destinatarios de las normas en situaciones de perplejidad normativa y, por lo tanto -según este último autor- estaríamos ante un problema de atipicidad por falta de tipicidad conglobante de la conducta del agente, ya sea que cumpla con uno de los deberes o con el otro ${ }^{12}$.

Alonso concluye que en el caso bajo análisis el agente no tiene la posibilidad teórico-normativa de satisfacer ambos deberes jurídicos al mismo tiempo (pagar/no pagar), ya que un deber es la negación del otro, por lo que, mientras una persona se encuentre ante esta situación de conflicto entre los deberes ya detallados, nunca actuará antijurídicamente. Así, concluye su investigación sosteniendo que el ciudadano "haga lo que haga (esto es, pague o no pague el cheque) no puede ser objeto de sanción penal por ausencia de antijuridicidad"13.

\section{Análisis Crítico de la posición de Alonso}

Alonso afirma que el agente del caso por él descripto, pague o no pague el cheque, no podrá ser objeto de sanción penal por ausencia de antijuridicidad, pero no especifica cuál es la causa de justificación aplicable, lo cual ya de por sí es criticable. Sobre todo cuando en el CP argentino existen normas expresamente legisladas que resultan prima facie aplicables para solucionar este problema, y que son consideradas mayoritariamente como causas de justificación, como por ejemplo las de los incs. $3^{\circ}$ y $4^{\circ}$ del art. 34 . No acudir a ellas, por lo tanto, exige una fundamentación de la que el trabajo de Alonso adolece, o que en todo

\footnotetext{
${ }^{12}$ Alonso, op. cit., p. 50. Sin embargo, y como enseguida se verá, la doctrina dominante, tanto en Argentina como en Alemania, entiende al problema de colisión de deberes como un caso de falta de antijuridicidad (por la existencia de una causa de justificación) o de falta de culpabilidad (por la inexigibilidad de una conducta conforme a derecho), y no como falta de tipicidad como lo sostiene Zaffaroni, quien con su idea de "tipicidad conglobante" representa una posición minoritaria en Argentina.

${ }^{13}$ Alonso, op. cit., p. 57.
} 
caso es incompleta y de dudosa consistencia, pues, en los resultados, su posición, al no apoyarse en una causa de justificación expresa, se acerca demasiado a aquella concepción -tan común en la doctrina alemana pero tan alejada del pensamiento positivista- que acepta a las llamadas "causas de justificación supralegales", como enseguida se demostrará.

Alonso, por otro lado, señala como fundamento de la solución de la impunidad de ambas conductas por ausencia de antijuridicidad la circunstancia de que el librador del cheque declarado en quiebra sí tiene la posibilidad fáctica de pagar o no pagar, pero no la posibilidad teóriconormativa de una u otra conducta, en tanto la afirmación de un deber importa la negación del otro. Y apoyándose en Roxin afirma que, para que una conducta pueda ser antijurídica, tiene que existir al menos la alternativa teórica de una conducta conforme a derecho ${ }^{14}$. Para ilustrar el problema, Alonso pone como ejemplo de caso inverso (esto es: imposibilidad fáctica pero posibilidad teórico-normativa) al supuesto del padre que no puede salvar a sus dos hijos pero salva a uno de ellos, y afirma -siempre siguiendo a Roxin-que el padre, por tener al menos la alternativa teórico-normativa de salvar a los dos hijos, actúa antijurídicamente, aunque sin culpabilidad ${ }^{15}$. Pero aquí no puede dejar de señalarse que esa no es la solución de Roxin, quien justamente elige ese caso para intentar demostrar que el padre que salva a uno de los dos hijos no actúa antijurídicamente. Y este malentendido por parte de Alonso se produce porque él pasa por alto una distinción, que es central para la doctrina alemana (y en particular para Roxin), a saber: si los deberes que colisionan son de acción o de omisión.

En efecto, puede decirse que la solución de Alonso (ausencia de antijuridicidad cualquiera sea la alternativa que el autor elija: pagar o no pagar) tiene por base aquella jurisprudencia y doctrina dominante que en Alemania se aplica para el caso de colisión de deberes de acción (aun de igual jerarquía) referidos al mismo bien jurídico ${ }^{16}$. Pero no es eso lo que ocurre en el caso propuesto por Alonso, y la solución por él

\footnotetext{
${ }^{14}$ Alonso, op. cit., p. 56.

15 Alonso, ibid.

${ }^{16}$ Sobre esto cf. Roxin, Claus, Derecho Penal. Parte General, t. I: Fundamentos. La estructura de la teoría del delito, trad. Luzón Peña y otros, Civitas, Madrid, 1997, $\S 16$, nm. 100 y ss., pp. 724 y ss.
} 
propugnada no resulta compatible con nuestro ordenamiento jurídico, como luego se verá.

En el caso de análisis se está ante una colisión entre un deber de acción y otro de omisión, es decir, entre un deber de pagar y un deber de no pagar. En el derecho penal alemán se regula, en el § 34 StGB, el estado de necesidad justificante, mediante el cual se exime de antijuridicidad a la conducta típica realizada por el agente que se encuentra ante una situación de peligro inminente, y no evitable de otra forma, para la vida, la integridad física, la libertad, el honor, la propiedad u otro bien jurídico, respecto de sí mismo o de otro, siempre y cuando el interés protegido prevalezca claramente respecto del afectado y en la medida que constituya un medio adecuado para evitar el peligro.

Así, Roxin sostiene que la jurisprudencia alemana, inicialmente (esto es: con anterioridad a la existencia del citado § 34 StGB), afirmó que la colisión de deberes se trataba como una forma de estado de necesidad supralegal ${ }^{17}$. Sin embargo, la norma vigente, en primer lugar, sólo hace referencia a colisión de intereses, no de deberes ${ }^{18}$; $\mathrm{y}$, en segundo lugar, establece claramente que debe efectuarse una ponderación de los intereses en conflicto. Por lo tanto, para la doctrina alemana la colisión de deberes (de acción) de igual o similar jerarquía encuentra su solución no en una causa de justificación específicamente prevista en la ley, sino en una construcción dogmática a partir de lo que el $§ 34$ StGB no regula, y por lo tanto se la considera una "causa de justificación supralegal"19.

Al respecto, Roxin afirma que "según la opinión actualmente dominante, sólo se puede hablar de colisión de deberes cuando existan dos deberes distintos de acción, de los que se puede cumplir uno de ellos" 20 . El mencionado autor, para justificar la tesis dominante, sostiene que "un deber de omisión lo infringe -a reserva de que haya una causa de justificación- todo el que ataca un bien jurídico ajeno; pero esos casos deben tratarse conforme al art. 34 y no precisan ninguna regulación especial. Lo mismo ocurre en el supuesto de colisión de un deber de

\footnotetext{
${ }^{17}$ Roxin, ibid, $\S 16$, nm. 100 y ss., pp. 724.

${ }^{18}$ Roxin, ibid, § 16, nm. 100 y ss., pp. 724.

${ }_{19}^{19}$ Así expresamente, entre otros, Roxin, op. cit., § 16, nm. 107, pp. 727 y ss.

${ }^{20}$ Roxin, ibid, § 16, nm. 101, p. 725.
} 
acción con uno de omisión... Esa colisión también debe resolverse sin más conforme al art. 34, de tal manera que en el caso de equivalencia de los bienes jurídicos tiene prioridad el deber de omisión: nadie puede p.ej. en el supuesto extremo de que se enfrente una vida contra otra vidamatar a una persona de quien no parte ningún peligro, para salvar de ese modo a otra persona" 21 .

Por lo tanto, en la legislación alemana, mediante el § 34 StGB -estado de necesidad justificante- se resolverían todas aquellas situaciones que se refieran a conflictos de deberes de rango claramente diferente, siempre y cuando no se trate de dos o más deberes de acción, de los que sólo se pueda cumplir uno de ellos. En estos casos, actuará justificadamente quien cumpla uno de esos deberes (de acción), aun cuando sea a costa del otro. Roxin asevera que, incluso en el caso de conflicto de deberes de acción equivalentes, uno de esos deberes es prioritario, puesto que prevalecerá el deber que el obligado elija a su arbitrio, sin que tenga que ser analizada la causa de su elección. En efecto, la conducta que se efectúe en un caso así estará justificada, porque en los casos de 'conflictos de deberes de acción' no existe ninguna colisión de deberes en sentido propio, sino que se trata de cumplir un deber ${ }^{22}$. Y aquí es cuando Roxin acude al ejemplo anunciado: si A tiene el deber de salvar a su hijo B y también el deber de salvar a su otro hijo $\mathrm{C}$ de una situación de peligro común para ambos, y salva sólo a B, actuará justificadamente (y no sólo sin culpabilidad, como Alonso refiere) respecto de la no salvación de $\mathrm{C}^{23}$.

Es cierto que otros autores sostienen que en el caso de conflicto entre deberes de acción equivalentes el sujeto obligado actúa siempre antijurídicamente, es decir, ya sea que cumpla alguno de los deberes o que no cumpla con ninguno. Roxin entiende, sin embargo, que sería injusto considerar antijurídica la acción realizada por un sujeto que hace todo lo posible para cumplir con su deber, y que, como consecuencia de ello, cumple al menos uno de los dos deberes a los que está obligado simultáneamente, puesto que de esa manera sería equiparado al que no hace absolutamente nada y por lo tanto incumple

\footnotetext{
${ }^{21}$ Roxin, ibid, § 16, nm. 102, p. 725.

${ }^{22}$ Sobre todo esto cf. Roxin, ibid., § 16, nm. 103, p. 726.

${ }^{23}$ Roxin, ibid., § 16, nm. 103, p. 726.
} 
ambos deberes ${ }^{24}$. Y esta es, precisamente, la razón que da Roxin para considerar lícita -y no sólo inculpable- a la conducta del sujeto del ejemplo.

A modo de síntesis de lo expuesto hasta aquí: para Roxin, si se da una colisión entre dos (o más) deberes de acción de igual o similar jerarquía y referidos a un mismo bien jurídico, debe considerarse lícita (esto es, no antijurídica) la conducta del sujeto cualquiera sea el deber que cumpla. Para Alonso, en cambio, esta misma solución corresponde para supuestos de colisión entre dos (o más) deberes de igual o similar jerarquía, aun cuando uno de ellos sea de acción y el otro de omisión (como de hecho sucede en el caso que él se propone analizar). Pues bien, esta solución de Alonso sería inaceptable en el derecho penal alemán, porque si realmente ambos deberes son de igual o similar jerarquía como él lo afirma- pero uno de ellos es de acción (pagar) y el otro de omisión (no pagar), entonces correspondería resolver el caso mediante el $\S 34$ StGB (estado de necesidad justificante), dado que, cuando colisionan dos deberes de igual o similar jerarquía en abstracto, pero uno de ellos es de acción y el otro de omisión, en concreto prevalece siempre -y claramente, como lo exige el $\S 34$ StGB- este último (entre matar y no matar prevalece no matar; entre pagar y no pagar prevalece no pagar, etc.); así, la clara diferencia de rango exigida por el § 34 StGB se da en el caso y corresponde entonces la aplicación de esta norma, como consecuencia de lo cual sólo estará justificado el agente si no paga. Es cierto que, en el caso de Alonso, uno y otro deber remiten a bienes jurídicos diferentes, por lo que la prevalencia necesaria del deber de omisión podría, en rigor, ser discutible. Pero no lo es menos que el $\S$ 34 StGB ha sido ideado sobre la base de la idea de que los intereses individuales prevalecen por sobre los colectivos (los bienes jurídicos allí mencionados son todos individuales: vida, libertad, honor, propiedad). De allí que, en ese sistema, frente a una colisión entre un deber de proteger, mediante omisión, un bien jurídico individual (la propiedad), y otro de proteger, mediante acción, un bien jurídico colectivo (la fe pública), lo correcto sería concluir que debe justificarse sólo el deber de omisión referido a un bien jurídico individual. Esta cuestión, con todo, será abordada más abajo nuevamente.

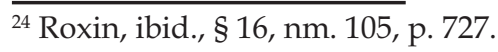

122 - Revista Discusiones N ${ }^{\circ} 9$ 
Hasta el momento, se ha hecho referencia únicamente a la forma en que el sistema jurídico alemán resolvería esta cuestión desde su ordenamiento penal, y se ha puesto de manifiesto la coincidencia entre la forma en que Alonso soluciona el conflicto entre un deber de acción y uno de omisión y la solución que en Alemania, según la doctrina y jurisprudencia dominantes, se resuelve un conflicto entre deberes de acción. Sin embargo, la legislación argentina (al igual que la de España $)^{25}$ prevé en su Código Penal, dentro de las conductas que considera justificadas, no sólo al estado de necesidad (art. 34 inc. $3^{\circ}$ ), como en el derecho alemán, sino también al cumplimiento de un deber (art. 34 inc. $4^{\circ}$ ). Así, si bien cabe coincidir con Alonso en que, prima facie, se está frente a un conflicto de deberes jurídicos, ha de rechazarse la solución a la que él arriba. Puesto que, a mi juicio, este problema se soluciona entre nosotros de lege lata a través de la aplicación de esta última norma del Código Penal argentino, que tiene por objeto solucionar precisamente esta clase de conflictos normativos. El art. 34 inc. $4^{\circ}$ del $\mathrm{CP}$ prescribe, en efecto, que no será punible quien actúe en cumplimiento de un deber. Esto significa que la conducta de quien obra en forma típica motivado por el cumplimiento de un deber se encuentra justificada, siempre y cuando la elección del deber jurídico cumplido sea la correcta.

Esta previsión del legislador argentino merece una interpretación diferente a la del derecho penal alemán, puesto que no cabría la posibilidad de incluir dentro de la figura del estado de necesidad justificante a una conducta típica realizada para dar cumplimiento a un deber jurídico en detrimento de otro, dado que el art. 34 inc. $3^{\circ}$ del $\mathrm{CP}$ argentino se refiere únicamente a casos de colisión de bienes o intereses, no de deberes. Es cierto que una parte de la doctrina -dentro de la cual se encuentra Bacigalupo- sostiene que incluir en forma específica al cumplimiento de un deber como causa de justificación (como eximente de la antijuridicidad) es superfluo ${ }^{26}$. No comparto, sin embargo, esa posición. Pues a mi criterio la norma del art. 34 inc. $4^{\circ}$ del

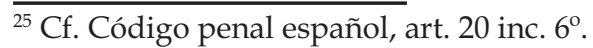

${ }^{26}$ Bacigalupo, Enrique, Derecho penal. Parte general, Hammurabi, Buenos Aires, 1987, p. 236. 
$\mathrm{CP}$ argentino es necesaria para, precisamente, resolver los conflictos normativos que -prima facie- surjan entre deberes de acción, como así también entre deberes de acción y de omisión.

Esta norma soluciona de manera muy simple la problemática planteada por Roxin, ya desarrollada; es decir: en nuestro sistema de normas penales no es necesario (ni posible) recurrir al estado de necesidad para justificar la colisión entre un deber de acción y uno de omisión, ni tiene que acudirse a una discutible construcción dogmática para fundar -vía dudosas "causas supralegales" de impunidad- la justificación de la conducta realizada cuando se trata de un cumplimiento de un deber de acción en detrimento de otro deber también de acción, en tanto el cumplimiento de uno implique el incumplimiento del otro. Es decir: a mi juicio es claro que la norma del art. 34 inc. $4^{\circ}$ del $\mathrm{CP}$ tiene por objeto resolver, precisamente, casos de colisión entre deberes, sean éstos de acción (ambos), o de acción y de omisión. Una norma como esta está ausente en la legislación alemana, y ello es justamente lo que, en ese país, provoca las dificultades interpretativas señaladas. Ahora bien, no obstante ello, el problema que se plantea en nuestro derecho penal es determinar, en caso de colisión entre deberes jurídicos, cuál de ellos es el que tiene que cumplir el agente para que el ordenamiento jurídico justifique su conducta.

Al respecto entiendo que habrá que efectuar, ante todo, una ponderación de los deberes en juego para determinar cuál de ellos es el que prevalece, y para ello será necesario valerse de diversos criterios, los que varían según cada caso concreto que se presente. Así, una vez que queden establecidos los criterios que a mi juicio determinan cuál de los deberes es el que prevalece, la solución del caso planteado por Alonso se presenta sencilla, mediante la aplicación de una norma expresamente prevista en nuestro derecho penal, y precisamente para estos casos de conflictos de deberes: el mencionado art. 34 inc. $4^{\circ}$ del CP. De tal modo, si el agente realiza la conducta adecuada (en el sentido planteado aquí), ese actuar típico no resultará punible, porque el ordenamiento jurídico prevé una causa de justificación para tales casos puntuales. Pero sí será punible si realiza la conducta inadecuada (es decir: si opta por el deber que normativamente no prevalece). Y a esto apuntaba una de las críticas iniciales al trabajo aquí analizado: dado precisamente que el art. 34 inc. 
$4^{\circ}$ del CP resulta prima facie aplicable para resolver, en materia penal, un conflicto entre deberes jurídicos, no se comprende la ausencia completa de argumentación por parte de Alonso para explicar por qué él considera que no es mediante esa norma que debe resolverse el conflicto en cuestión.

A mi juicio, la vigencia del art. 34 inc. $4^{\circ}$ del $\mathrm{CP}$ en nuestro sistema jurídico hace que, en caso de conflicto entre deberes jurídicos, rija ante todo el criterio de la especificidad: el deber que prevalece es el específico sobre el general ${ }^{27}$. Sólo para el caso de que no pueda establecerse (o al menos no con claridad) cuál es el deber más específico, rige el criterio de la jerarquía del bien jurídico involucrado. Esa es precisamente la razón de ser de la norma prevista en el art. 34 inc. $4^{\circ}$ del CP. En efecto: dado que todos los habitantes de la Nación están obligados a cumplir con los deberes establecidos por el Derecho $(\mathrm{CN}$, art. 19, segunda parte a contrario sensu), si se plantea un conflicto de deberes es porque uno es más específico o más importante que el otro. Pero si uno es claramente más específico, ese prevalece, aunque el otro sea de mayor jerarquía, pues de lo contrario el Estado no podría cumplir con ciertas finalidades que le son propias.

En efecto: el deber del policía de aprehender y por tanto de privar de la libertad a una persona a quien sorprende cometiendo un delito prevalece, por su especificidad, frente al deber general de respetar la libertad ajena; el deber específico del oficial de justicia de ingresar a una morada para embargar bienes prevalece sobre el deber general de no violar el domicilio, etc. Y el deber específico del declarado en quiebra de no pagar un cheque prevalece sobre el deber general de no violar la fe pública.

El carácter dirimente de este criterio se aprecia claramente con estos ejemplos, puesto que es evidente que el deber de no violar el domicilio ajeno, prescripto incluso constitucionalmente, es de mayor jerarquía que el de asegurar un derecho patrimonial futuro, previsto en un código de procedimiento, pero, no obstante ello, en el caso del ejemplo este último prevalece sobre aquel. La razón de ser de la primacía del deber específico sobre el de mayor jerarquía reside, pues -y como se

${ }^{27}$ Nuñez, Ricardo C., Derecho penal argentino, parte general, t. I, Buenos Aires, 1964, p. 400. 
dijo-, en la necesidad estatal de cumplir con determinadas finalidades que le son propias (supuesta su conformidad constitucional), aun en confrontación con otros deberes generales que remiten a bienes jurídicos de jerarquía mayor.

Lo mismo se observa si analizamos el ejemplo del policía, puesto que, claramente, el deber de respetar la libertad ambulatoria de los ciudadanos, previsto expresamente en tratados internacionales incorporados a la Constitución (v.gr. CADH, art. 7.2), es de mayor jerarquía que el deber del policía de evitar que se cometan delitos o de reprimir la delincuencia sorprendida en flagrancia, previsto en leyes locales (ley orgánica de la Policía de la Provincia de Córdoba № 6701, arts. 6 y 7; CPP Cba., arts. 323, $2^{\circ}$ párrafo y 324 inc. $7^{\circ}$ ). Sin embargo, en estos casos puntuales y en virtud de lo prescripto por una norma, un reglamento, una sentencia, etc., estos deberes de mayor jerarquía ceden ante otro específicamente determinado que le compete a una persona individualizada. Y la especificidad de un deber depende del grado de generalidad (o especificidad) de la norma que lo contiene. Así, y por regla, las normas constitucionales serán más generales que las del derecho penal de fondo, éstas más que las de los códigos de procedimiento y éstas más que las de las leyes orgánicas de funcionamiento de determinadas instituciones, etc.

Y existen incluso deberes más específicos aún que los establecidos por las normas generales de mayor especificidad, valga el juego de palabras. Así, sabido es que Kelsen sostiene que las normas más específicas son las sentencias judiciales (o administrativas), en tanto ellas establecen una "norma individual" que concretiza la norma general para ese caso y para una persona individualizada (o varias) en una situación particular ${ }^{28}$. Es decir, esa persona tendrá un deber que cumplir única y exclusivamente a partir de esa sentencia. Si ese deber colisiona con otro que surge de normas generales, prevalecerá el más específico

${ }^{28}$ Cf. Kelsen, Hans, Teoría pura del derecho, $2^{\mathrm{a}}$ edic., trad. Roberto Vernengo, UNAM, México, 1979, p. 240: “...De allí que la aplicación de una norma general a un caso concreto consista en la producción de una norma individual, en la individualización (o concretización) de la norma general" (el paréntesis es del original). 
de la norma individual. En el Derecho se sigue, así, la regla de la especificidad, en el sentido de que la ley especial deroga a la ley general.

Por esta razón, y para volver al caso en examen, a partir del momento en que el agente es declarado en quiebra mediante una sentencia judicial que así lo determina, tiene el deber específico de no pagar el cheque en cuestión. En efecto, ese sujeto, desde el momento en que es declarado en quiebra por sentencia judicial, tiene ese deber que surge de esa sentencia, y que por ello es específico a su condición de quebrado. Por esta razón, desde el nacimiento de este deber específico, el deber general (de pagar) cede y la conducta típica en relación con el art. 302 del CP (la de no pagar) estará justificada, en virtud de lo expresamente previsto en el art. 34 inc. $4^{\text {o }}$ del CP. ${ }^{29}$ Pero si paga, su conducta, por todo lo expuesto, será típica y antijurídica, sin perjuicio de lo que pueda eventualmente discutirse respecto de su culpabilidad, según cómo se presente el caso en relación con la problemática del error de prohibición.

Puede ocurrir, sin embargo -y como ya fuera advertidoque en un caso concreto de colisión de deberes no pueda establecerse con suficiente claridad cuál de ellos es el más específico. Ello ocurre, por ejemplo, cuando colisionan el deber de testimoniar verazmente en juicio con el de no vulnerar el honor de las personas. Ambos son establecidos por normas del CP y tienen por tanto el mismo nivel de generalidad (y de especificidad). En esos casos, entonces, rige el criterio de la mayor jerarquía del bien jurídico al que remite el deber: el ciudadano debe decir la verdad al testimoniar aunque con ello injurie a alguien, porque para el CP es más importante que se respete la debida administración de justicia que el honor, como lo deja en claro la diferencia de los montos de las penas para uno y otro delito: un mes a cuatro años de prisión para el falso testimonio simple (uno a diez años para el agravado) y

${ }^{29}$ Con ello la solución aquí propuesta no se compromete con la tesis, criticada por Alonso, que sostiene la completitud a priori de los sistemas jurídicos. Simplemente se sostiene que este caso concreto de colisión de deberes puede ser adecuadamente resuelto con la aplicación de una norma del CP (el art. 34 inc. $4^{\circ}$ ) cuyo objeto específico es precisamente resolver conflictos de colisión de deberes. 
un mes a un año de prisión para la injuria (CP, arts. 275 y 109, respectivamente $)^{30}$.

Y es posible, también, que el deber más específico sea también el que remita a un bien jurídico de mayor jerarquía, en cuyo caso no habrá duda de que ese es el deber que prevalece. Eso es precisamente lo que ocurre con el caso propuesto por Alonso, pues allí el deber de no pagar (para no vulnerar la propiedad) no sólo es el más específico por provenir de una norma individual (sentencia judicial), sino también el de mayor jerarquía. En efecto, el bien jurídico protegido por el artículo 176 del CP es la propiedad, y el que protege el art. 302 es la fe pública. Ya ha sido expuesto que Alonso sostiene que no es adecuado utilizar este criterio para determinar cuál de esos deberes es el preponderante. Sin embargo, en mi opinión sí es posible, en el conflicto de deberes que Alonso plantea, determinar cuál de los bienes jurídicos a los que remiten los deberes en juego es el jerárquicamente superior.

Así, puede decirse que, en primer lugar, la propiedad está protegida explícitamente en la Constitución Nacional (art. 17), mientras que esto no ocurre con la fe pública. En segundo lugar, debe tenerse en cuenta que, en un Estado de derecho (y tal como el derecho penal alemán lo ha dejado muy en claro a través del $\S 34$ StGB), los bienes jurídicos individuales tienen como mínimo una primacía débil o prima facie sobre los bienes jurídicos colectivos. Sobre esta cuestión, Alexy sostiene en efecto que, en un Estado de derecho, "existe... una precedencia general prima facie a favor de los derechos individuales. Esta precedencia prima facie se expresa en una carga de la argumentación a favor de los derechos individuales y en contra de los derechos colectivos" ${ }^{31}$. En efecto, la propiedad privada de los acreedores del declarado en quiebra es un bien jurídico individual que, en este caso concreto, prevalece sobre la fe pública, que es un bien jurídico colectivo, puesto que, por fundar un

${ }^{30}$ Sobre la importancia de las escalas penales previstas en abstracto para determinar la mayor o menor jerarquía del bien jurídico (y del deber correlativo) de que se trate se ha pronunciado el mismo Alonso, en op. cit., p. 51-52.

${ }^{31}$ Alexy, Robert, El concepto y la validez del derecho, trad. Jorge M. Seña, Gedisa, Barcelona, 1994, p. 207. No es este el lugar para analizar en profundidad las razones de esta precedencia prima facie a favor de los bienes o derechos individuales. Para ello cf. Alexy, ibid., esp. pp. 200 y ss. 
Estado de derecho, ha de afirmarse que nuestro sistema constitucional protege en primera medida y con mayor intensidad al individuo.

Queda claro, pues, que entre el deber de pagar (para proteger la fe pública) y el de no pagar (para proteger la propiedad), este último es tanto el más específico como el de mayor jerarquía, por lo que resulta prevaleciente con respecto al anterior. En consecuencia, cabe afirmar que la fe pública, en este caso concreto, se encuentra obligada a 'soportar' el actuar típico del agente que haya emitido un cheque sin provisión de fondos, declarado en quiebra y con posterioridad intimado al pago. $\mathrm{O}$-lo que es lo mismo- en dicha situación el cumplimento del deber de no pagar el cheque por parte del agente declarado en quiebra en resguardo del patrimonio de sus acreedores justifica el incumplimiento del deber de pagarlo. Es decir: la acción típica en la que incurre el agente al no pagar el cheque en detrimento de la fe pública no es antijurídica en nuestro sistema penal, pero sí sería antijurídico el accionar del agente si pagara el cheque, pues en ese caso estaría dando cumplimiento al deber menos prevaleciente, tanto por el argumento de la especificidad como por el de la jerarquía.

\section{Conclusión.}

Sostengo entonces que el caso planteado por Alonso no debe resolverse como el autor lo plantea, es decir: que haga lo que haga el agente (pague o no pague el cheque), su conducta no será antijurídica. Ello importa, a mi juicio, pasar por alto la existencia, en nuestro ordenamiento jurídico, de una norma prevista expresamente para resolver esta clase de colisiones entre deberes jurídicos: el art. 34 inc. $4^{\circ}$ del CP. Según la interpretación aquí efectuada de dicha norma, debe acudirse ante todo al criterio de la especificidad para determinar cuál es el deber prevaleciente, o en su caso al criterio de la jerarquía si no fuera claro que uno de los deberes es más específico que otro. Puede ocurrir, por cierto, que un mismo deber sea el más específico y también el superior en jerarquía, en cuyo caso no habrá duda de que ese será el deber prevaleciente. Es lo que ocurre precisamente con el caso en examen, en el cual el deber de no pagar es tanto el más específico como 
el jerárquicamente superior. Por ello es que el deber más general y jerárquicamente inferior de pagar el cheque (CP, art. 302) cede frente al deber más específico y jerárquicamente superior de no pagarlo, conducta ésta que, aunque resulte típica en relación con el art. 302 del CP, estará justificada por el ordenamiento jurídico, en virtud de lo dispuesto por el art. 34 inc. $4^{\circ}$ del CP: actuación en cumplimiento de un deber. Por el contrario, el agente actuará antijurídicamente si paga el cheque, porque en tal caso cumplirá un deber general (y jerárquicamente inferior) en desmedro de uno específico (y jerárquicamente superior) que a él le compete. 